\title{
Antibiotic stewardship in a paediatric hospital
}

\author{
Susan Richardson MD CM, Kathryn Griffiths BSP
}

$\mathrm{I}$

nfectious diseases comprise a major percentage of paediatric illnesses as infections in out-patients, illnesses requiring hospitalization for treatment and nosocomially acquired infections. Although a significant percentage of infectious diseases are of viral etiology, initial empirical therapy for febrile undiagnosed illnesses and for presumed or proven bacterial infections results in widespread use of antimicrobials. In contrast to the beneficial effects of antibiotics are their expense, their adverse effects and their contribution to the emergence of increasingly drug-resistant organisms. Strategies to enhance the appropriate use of antimicrobials are most evident in hospitals such as The Hospital for Sick Children - a tertiary care paediatric hospital whose infrastructure supports and encourages proper use. The use of many of the following strategies (1) has been shown to reduce drug expenditures and overall hospital costs by improving patient care.

\section{TABLE 1}

Antibiotic stewardship at The Hospital for Sick Children

\begin{tabular}{|c|c|}
\hline Stewardship strategies & Description \\
\hline \multirow[t]{3}{*}{ Pharmacy \& Therapeutics Committee } & Has broad representation \\
\hline & Approves The Hospital for Sick Children formulary \\
\hline & $\begin{array}{l}\text { Incorporates recommendations from The Antibiotic Subcommittee, Drug Information Service and The } \\
\text { Drug Use Evaluation Committee }\end{array}$ \\
\hline \multirow[t]{3}{*}{ The Hospital for Sick Children Formulary } & $\begin{array}{l}\text { Includes antimicrobials that have been approved by the Pharmacy \& Therapeutics Committee with } \\
\text { dosing guidelines, specific administration recommendations and precautions for use }\end{array}$ \\
\hline & $\begin{array}{l}\text { Includes list of restricted drugs; use permitted according to predetermined clinical indications, other } \\
\text { indications limited to approval by Division of Infectious Diseases }\end{array}$ \\
\hline & Published yearly \\
\hline \multirow[t]{2}{*}{ Drug Information Service } & $\begin{array}{l}\text { Performs independent literature-based, comprehensive review of all antibiotics being considered for } \\
\text { formulary inclusion }\end{array}$ \\
\hline & Publishes and edits formulary \\
\hline \multirow[t]{5}{*}{ Antimicrobial use guidelines } & Included in the formulary; new guidelines published as pocketcards until a new formulary is published \\
\hline & Initial empirical antimicrobial therapy for hospitalized children (23 disease indications) \\
\hline & $\begin{array}{l}\text { Prophylaxis: cardiovascular surgery, general surgery, orthopedic surgery, plastic surgery, endocarditis } \\
\text { prophylaxis }\end{array}$ \\
\hline & Management of presumed meningitis \\
\hline & Management of neutropenic patients with fever \\
\hline
\end{tabular}




\section{TABLE 1 continued}

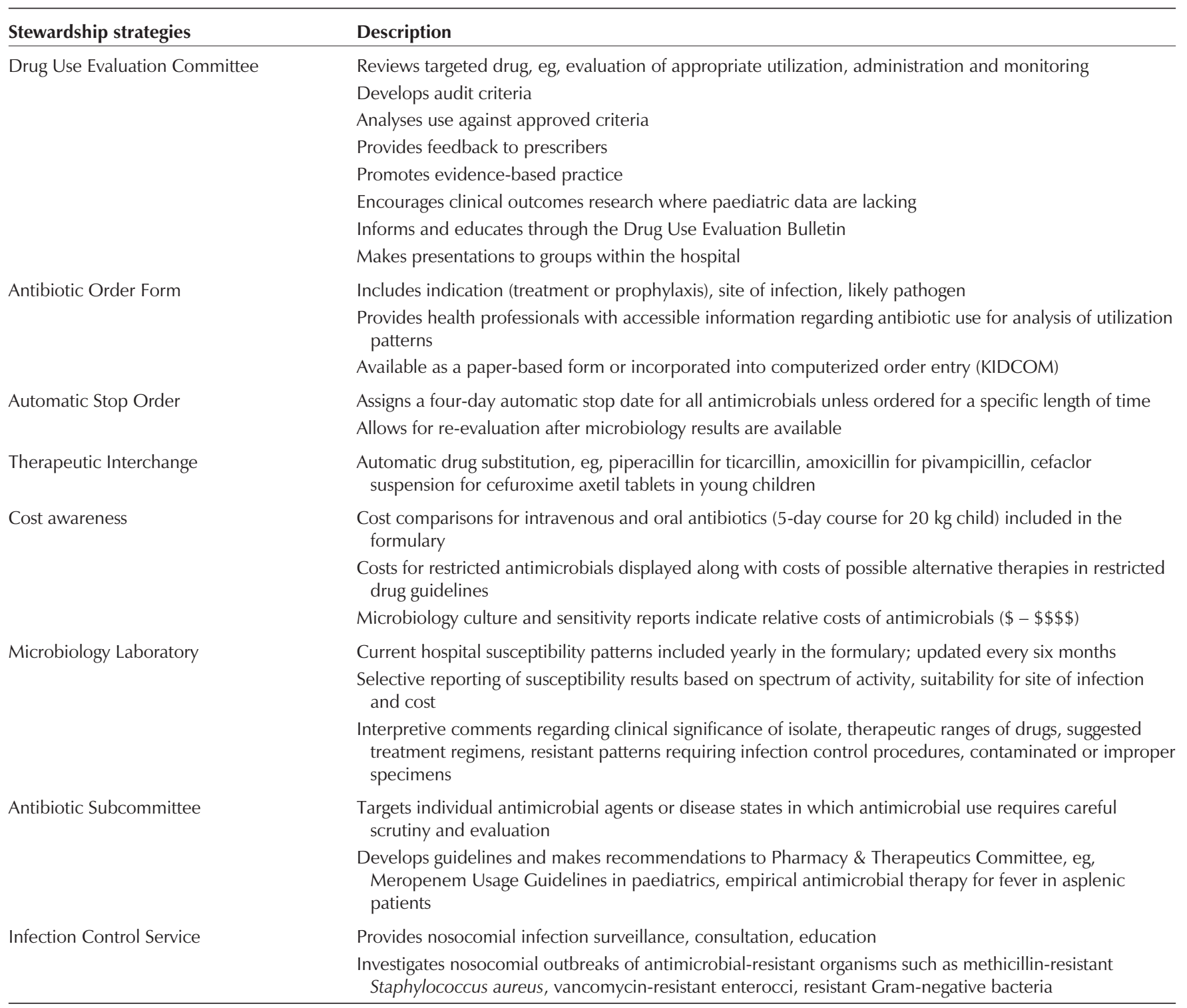

The core of the stewardship program is the Pharmacy and Therapeutics Committee (P\&T), which has broad representation from all clinical areas and reports to the Medical Advisory Committee via the Patient Care Committee. Reporting to the P\&T are the Drug Use Evaluation Committee (DUE), the Antibiotic Subcommittee and the Drug Information Service. The Department of Pharmacy, the Divisions of Infectious Diseases and Microbiology and the Infection Control Service play key roles in these core committees to produce the array of continuously operating strategies (Table 1). Examples of DUE audits that have had significant effects on curbing inappropriate use of antimicrobials are targeted reviews of acyclovir, cefuroxime, ceftazidime, clindamycin, vancomycin and liposomal amphotericin B. Other audits that have significantly decreased costs are guidelines for reduced monitoring of gentamicin and vancomycin serum concentrations, standardized drug dosage and frequency guidelines (within defined weight ranges), and drug wastage studies (ie, antimicrobials).

These initiatives cumulatively produce significant financial savings and unmeasured but critical benefits to patient care and more than support the salary of a part-time DUE pharmacist. The process of evaluation and re-evaluation also permits the consideration of newer, more effective, but usually more expensive antimicrobials for the formulary. Continuing the cyclical process and maintaining a core of committed individuals are key to the success of such a program.

\section{REFERENCES}

1. Diamond SA, Hales BJ. Strategies for controlling antibiotic use in a tertiary-care paediatric hospital. Paediatr Child Health 1997;2:181-6. 


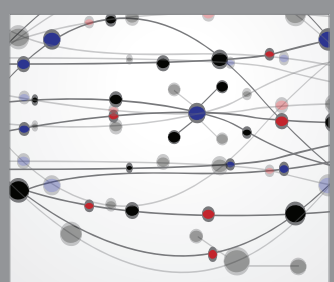

The Scientific World Journal
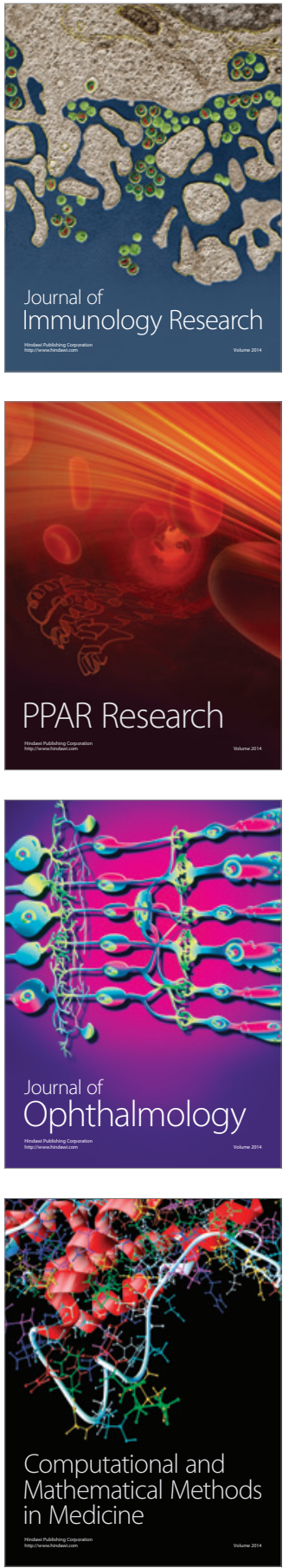

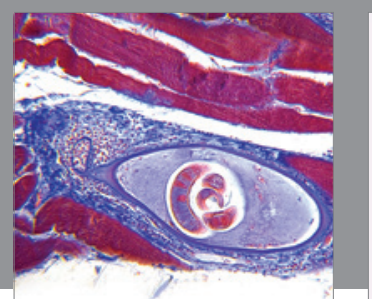

Gastroenterology Research and Practice

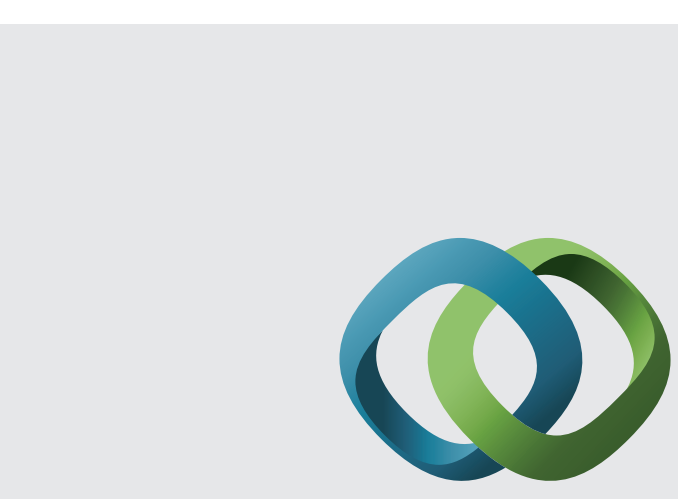

\section{Hindawi}

Submit your manuscripts at

http://www.hindawi.com
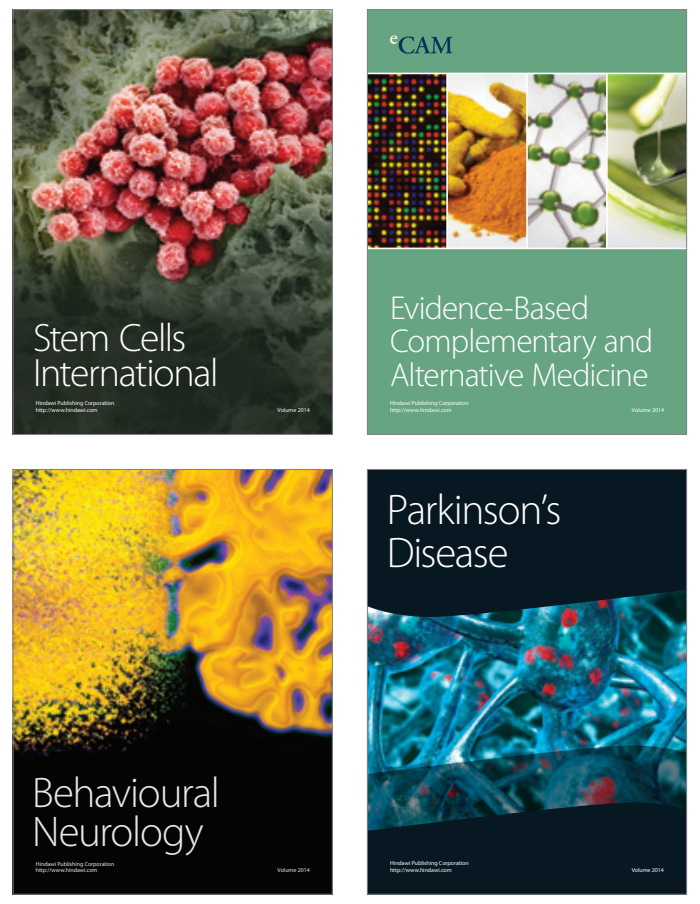
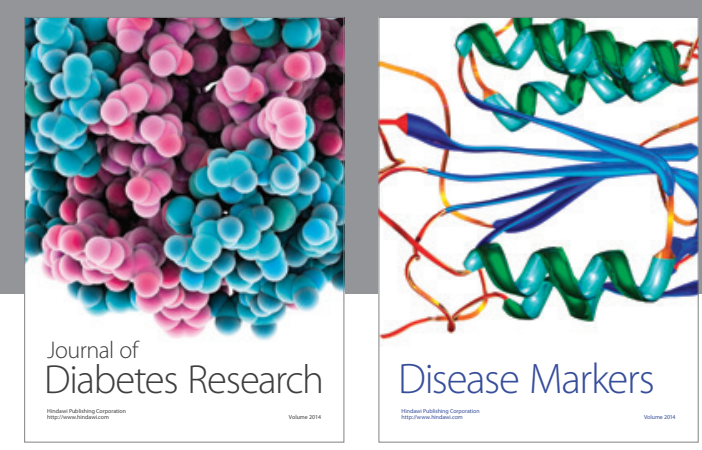

Disease Markers
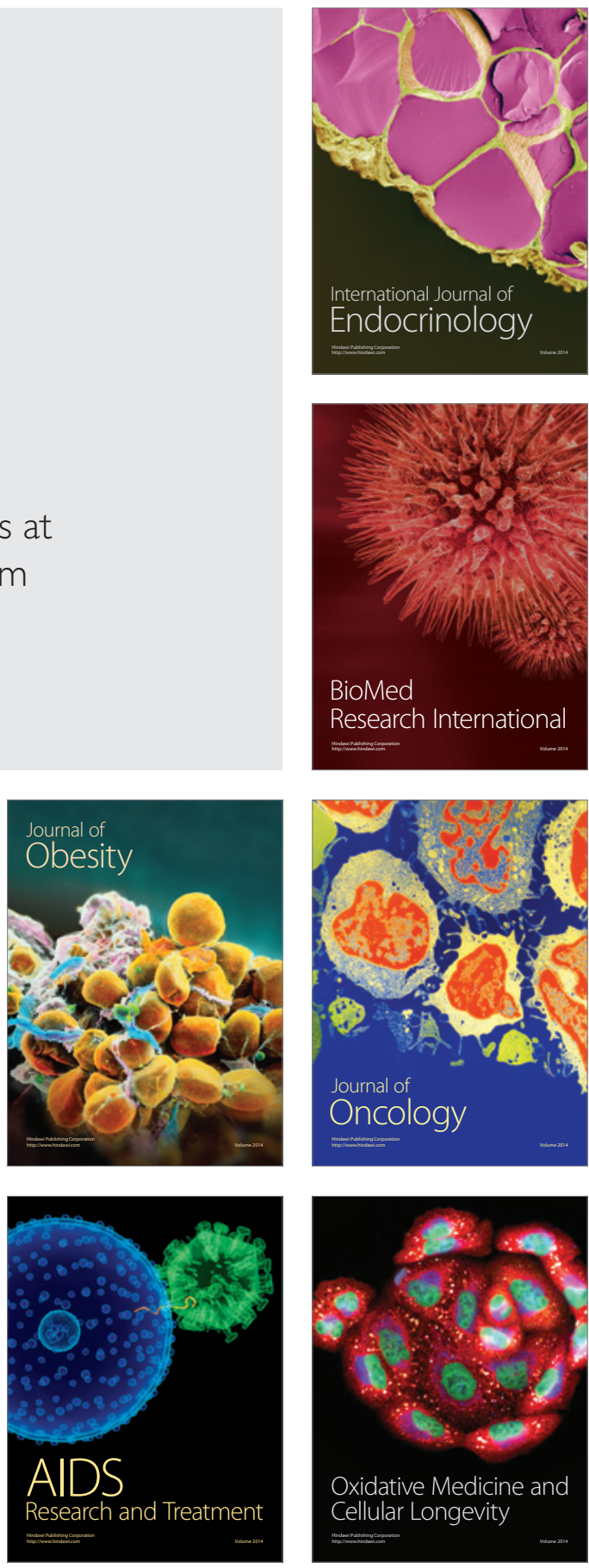